TITLE:

The Effect of Freeze-Thaw and Moisture on Soil Strength Index of Cutting Slope

$\operatorname{AUTHOR}(\mathrm{S})$ :

Guo, Ying; Shan, Wei

CITATION:

Guo, Ying ...[et al]. The Effect of Freeze-Thaw and Moisture on Soil Strength Index of Cutting Slope. Matsue Conference Proceedings (The Tenth International Symposium on Mitigation of Geo-disasters in Asia 2012: 131-138: 共同研究（一般 研究集会) 24K-02.

ISSUE DATE:

2012-10-08

URL:

http://hdl.handle.net/2433/180404

RIGHT: 


\title{
The Effect of Freeze-Thaw and Moisture on Soil Strength Index of Cutting Slope
}

\author{
Ying Guo and Wei Shan
}

\begin{abstract}
It is the main problem for highway in seasonal frozen regions that soil cutting slope instability causing by freeze-thaw. The change in soil moisture is important factor for soil cutting slope landsliding. Relying on the silty clay slope, which is in the highway expansion project from Fangzheng to Harbin, using field monitoring, and indoor test, the soil moisture varying with ground temperature and the effect of soil moisture on soil physical and mechanical indexes were studied. Field monitoring result indicates that, during the process of soil freezing, there will appear the cracks caused by temperature shrinkage which destroy integrated strength of the slope. Moisture migrates to the freezing-front due to the cracks caused by temperature shrinkage. In the melting period of spring, because of the accumulating water within the cracks, and longer duration of zero temperature below the surface, the melting water is hampered, when soil body temperature reaches $0.1{ }^{\circ} \mathrm{C}$, the frozen water within the soil body melt rapidly. All of these leads to the water content in shallow slope too high, soil shear strength decreases. Triaxial test results show that: When the soil water content is less than the optimum water content, the soil cohesion increases with increasing moisture, when the soil water content is bigger than the optimum water content, the soil cohesion decreases with increasing moisture. The peak value of soil cohesion is near the optimum water content. The internal friction angle of soil decreases with the increasing moisture. Soil cohesion decreases with the increasing freeze-thaw cycles.
\end{abstract}

Keywords Highway - Cutting slope - Silty clay · Freeze-thaw - Soil moisture

Y. Guo · W. Shan $(\bowtie)$

Northeast Forestry University, Harbin 150040, China

e-mail: shanwei456@163.com 


\section{Introduction}

Soil cutting slope shallow land sliding occurs frequently in seasonal frozen areas of Northeast China (Wu et al. 2006; Liu and Wang 2006). The main reason is the moisture transfers to the freezing front during the freezing period, which results in water content increasing in somewhere of shallow slope, then frost heaving occurs under subzero temperature. The association and arrangement among soil particles was changed by frost heaving, then the mechanical properties of the soil changed also (Shan et al. 2009). In the melting period of spring, the frozen layers in shallow slope thawed influenced by kinds of factors such as precipitation, increasing temperature and so on. The melting water was hampered by unfrozen layer under them during their infiltration downward, results in the water content increasing rapidly in the layer between melt layer and frozen layer, and reaching saturation or super saturation state, then the effective stress within the slope reduced, the partial or whole of the shallow slope slide down along the "water saturation layer" under gravity (Niu et al. 2004).

The study of the stability of permafrost slopes appeared earlier (Tarr 1897; McRoberts and Morgenstern 1974; Clark 1988; Zhou and Guo 1982), but mainly is in permafrost plateau (Zhu et al. 1996; Wang and French 1995; Niu and Cheng 2002; Li and Zhao 2002). There is difference between instability in seasonal frozen region and instability in permafrost, mainly is larger changes in temperature and repeated freezing-thawing cycles, which has obvious seasonal characteristics.

Relying on the highway expansion project from Fangzheng to Harbin, the study area is located on the side of Widening from K560 +090 to K565 +690. The terrain graph fluctuation of study area is bigger, the soil of it is sandy clay, whose natural density is $1.8-2.1 \mathrm{~g} / \mathrm{cm}^{3}$, the average height of the cutting slope is $5-15 \mathrm{~m}$, and the average ratio of the slope is $1.5-1.75$.

Through on-site investigation, monitoring water content and ground temperature in shallow slope, indoor test of soil physical and mechanical, the soil physical and mechanical nature varied with water content and freeze-thaw cycle, as well as the changes of soil moisture in freeze-thaw cycles.

\section{Monitoring of Ground Temperature and Soil Moisture on the Slope}

According to meteorological data in Heilongjiang Province, for the ground within $20 \mathrm{~cm}$ below the surface, subzero temperature begins to appear in early November every year, and above zero temperature appears in end of March of next year. The maximum freezing depth is about $1.9 \mathrm{~m}$. According to field investigation, the sliding surface of the cutting slope is about 1-1.5 $\mathrm{m}$ deep from the slope surface, and the thickness of slip zone is $10-25 \mathrm{~cm}$.

In order to study the effect of weather temperature and plant on ground temperature and soil moisture, two study sites were selected, one is in K560 + 700 (site A, height 

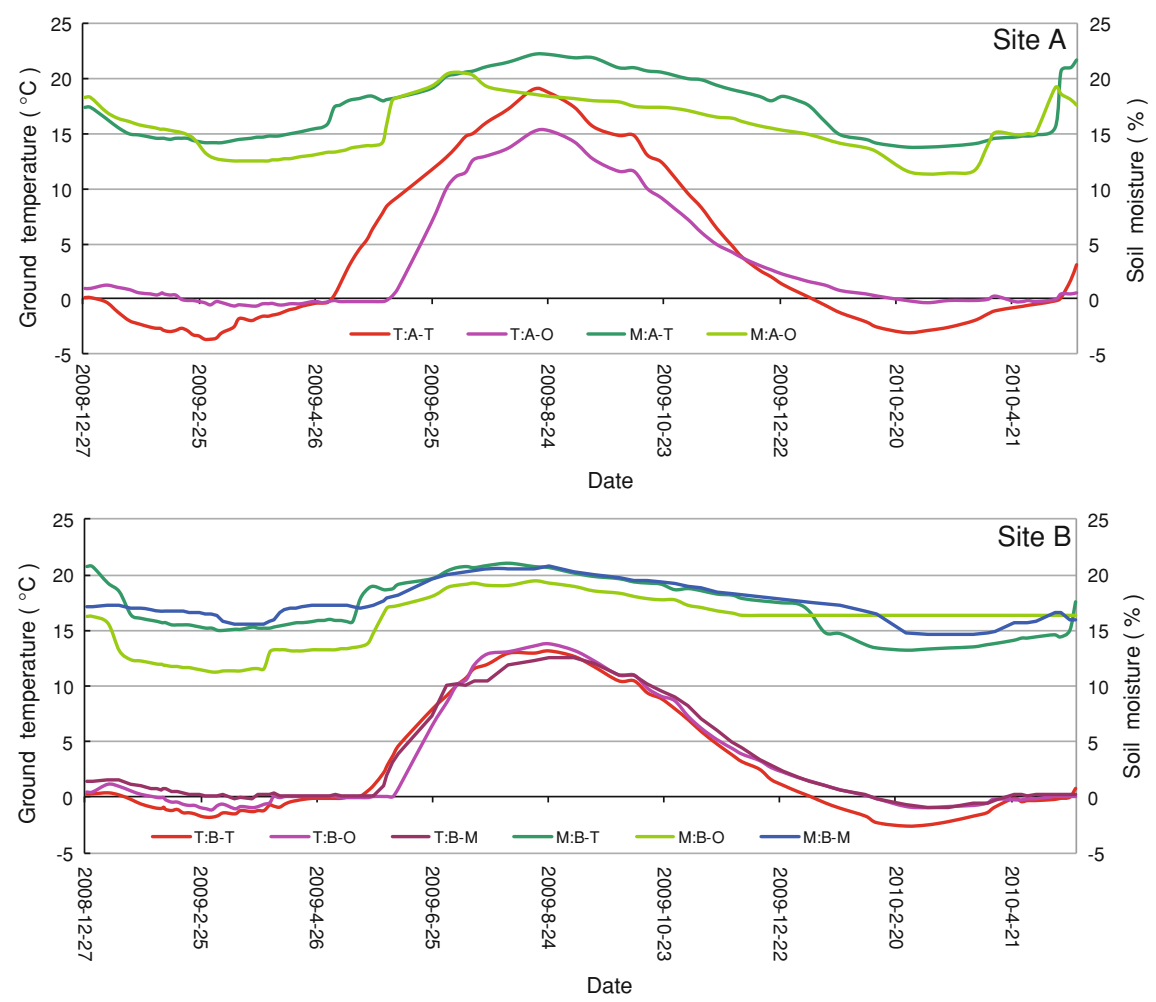

Fig. 1 The curves of ground temperature, soil moisture in $1.4 \mathrm{~m}$ depth varying with time

$5.6 \mathrm{~m}$, slope ratio 1.75) which planted grass, anther is in $\mathrm{K} 563+870$ (site B, height $15.3 \mathrm{~m}$, slope ratio 1.75) which planted Lespedeza. On both site, temperature sensors and moisture sensors were buried in the depth of 0.6, 1.4, $2.2 \mathrm{~m}$ separately. The sensors in different depth are all in the same drilling hole, site $B$ have three drilling holes which located on top (B-T), middle (B-M) and toe (B-O) of the slope separately. Site A only has two holes (A-T, A-O) and hasn't the hole in middle of the slope. From January 2009 to June 2010, the monitoring of ground temperature and soil moisture of five drilling holes was conducted. Among them, the value of the $1.4 \mathrm{~m}$ depth has the most representative, because it is above the maximum freezing depth, as well as near the sliding surface which known from the field investigation above. The next analysis is about the value of $1.4 \mathrm{~m}$ depth, and the curves can be seen in Fig. 1.

\subsection{Variation of Slope Ground Temperature}

In spring of 2009 and 2010, it can be seen from Fig. 1 that, in site A, the lowest ground temperature of two springs was $-3.7^{\circ} \mathrm{C},-3.1{ }^{\circ} \mathrm{C}$, which was found in A-T, 
and happened on March 1st, 2009 and February 25th 2010. The lowest ground temperature of A-O was $-0.6{ }^{\circ} \mathrm{C}$ and $-0.3{ }^{\circ} \mathrm{C}$, which happened on March $2 \mathrm{nd}, 2009$ and April 23rd 2010. In site B, the lowest ground temperature of two springs was $-1.8{ }^{\circ} \mathrm{C},-2.6^{\circ} \mathrm{C}$, this is found in B-T, and happened on the same date with A-T. The lowest ground temperature of A-M was $-1.1{ }^{\circ} \mathrm{C},-0.9^{\circ} \mathrm{C}$ which happened on March 2nd, 2009 and March 8th 2010. The lowest ground temperature of A-O was $-0.9{ }^{\circ} \mathrm{C},-1.6{ }^{\circ} \mathrm{C}$ which happened on March 1st, 2009 and March 3rd 2010. Since after these dates, the ground temperature of the measuring point begin to go up slowly, and go into the stage of above zero temperature one by one.

The order of appearing above zero temperature for five drilling holes is A-T, B-T, B-M, A-O, B-O, and corresponding appearing time is May 5th, May 11th, May 25th, June 4th, June 7th in 2009. Since after these dates, the ground temperature of five drilling holes begin to rise significantly. It's worth noting that, from top to toe of the slope, the time interval of appearing above zero temperature is about 30 days. Secondly, there is a longer duration of zero temperature.

In summer of 2009, it can be seen from the Fig. 1 that, In site A, the highest ground temperature was $19.1{ }^{\circ} \mathrm{C}, 15.3{ }^{\circ} \mathrm{C}$, which happened on August 16th and August 24th. In site $\mathrm{B}$, the highest ground temperature was $13.2{ }^{\circ} \mathrm{C}, 12.6^{\circ} \mathrm{C}$ and 13.8 ${ }^{\circ} \mathrm{C}$, which all happened on August 24th. It is worth noting here, the difference of the highest ground temperature between site A (with turf) and site B (with Lespedeza) is $6.5^{\circ} \mathrm{C}$.

As the weather turns to autumn, the order of appearing subzero temperature for five drilling holes in is A-T, B-T, B-M, B-O, A-O, and corresponding appearing time is January 8th, January 10th, February 7th, February 7th, February 17 th in 2010. Since after these dates, the ground temperature of the measuring point begin to go down continuously.

It can be seen from above analysis that, for the ground temperature in $1.4 \mathrm{~m}$ depth, whose on the top of the slope is affected by the weather temperature mostly, then is in middle of and on toe of the slope. Secondly, the kind and density of the plant on the slope also affect the ground temperature in $1.4 \mathrm{~m}$ depth. Thirdly, it is in spring that there is a longer duration of zero temperature in $1.4 \mathrm{~m}$ depth of the slope, but in autumn there has not.

\subsection{Variation of Slope Soil Moisture}

It can been seen from Fig. 1 that, during the freezing period, the soil moisture curve has a sharp declining when ground temperature is about $0{ }^{\circ} \mathrm{C}$. After that, the ground temperature declines gentle until reaches a minimum value, then the curve rise again slowly, as soon as ground temperature is over the zero temperature, the curve goes up rapidly.

For site A, in 2009 spring, the soil moisture of A-T goes up from $16 \%$ (May 2nd) to $17.4 \%$ (May 5th), at same time, corresponding ground temperature goes up from $-0.3{ }^{\circ} \mathrm{C}$ to $0.3{ }^{\circ} \mathrm{C}$. The soil moisture of A-O goes up from $13.9 \%$ (May 
30th) to $18 \%$ (June 4th), the corresponding ground temperature goes up from $-0.2{ }^{\circ} \mathrm{C}$ to $0.2{ }^{\circ} \mathrm{C}$. After that, the curve of soil moisture goes up slowly until close or over the value of plastic limit of the soil. The scene situation is, after 2009 spring, there appears cracks near site A $(\mathrm{K} 560+420-\mathrm{K} 560+550)$, then there occur landslide on 7th May 2010.

For site B, in 2009 spring, the moisture curve of B-T has one uplift process, which like site A, but the moisture curve of B-M and B-O have two uplift processes, details are as follows, the soil moisture of B-T go up from $15.8 \%$ (May 14th) to $19 \%$ (May 25 th), then the rise turn to gentle, at same time, corresponding ground temperature goes up from $0{ }^{\circ} \mathrm{C}$ to $0.1{ }^{\circ} \mathrm{C}$, and keeps straight up till to late July. The soil moisture of B-M first goes up from 15.6\% (March 29th) to $16.9 \%$ (April 9th), corresponding ground temperature go up from $-0.2{ }^{\circ} \mathrm{C}$ to $0.1{ }^{\circ} \mathrm{C}$, next follows a smooth uplift process, then goes up again from $17.3 \%$ (May 25th) to $19.6 \%$ (June 24th), corresponding ground temperature go up from $-0.1{ }^{\circ} \mathrm{C}$ to $1{ }^{\circ} \mathrm{C}$. The soil moisture of B-O go up from $11.5 \%$ (March 29th) to $13.2 \%$ (April 3th), corresponding ground temperature go up from $-0.9{ }^{\circ} \mathrm{C}$ to $0.1{ }^{\circ} \mathrm{C}$, next also follows a smooth uplift process, then goes up again from $13.8 \%$ (May 22th) to $17.2 \%$ (May 30th), corresponding ground temperature go up from $0.1{ }^{\circ} \mathrm{C}$ to $6.4{ }^{\circ} \mathrm{C}$.

It can be seen from above analysis that, soil moisture rises up quickly when ground temperature is above $0.1{ }^{\circ} \mathrm{C}$. The moisture of B-T and A-T begin to rise as soon as ground temperature has above zero temperature, and turn to gentle in 3-10 days. The moisture of B-M and B-O increased $1.3 \%$ and $1.7 \%$ when ground temperature rise up to $0.1{ }^{\circ} \mathrm{C}$, but the difference is the ground temperature here continued to maintain near $0.1{ }^{\circ} \mathrm{C}$ for 19 days and 65 days separately, then rise up again, during this period, the moisture of B-M and B-O rise up again for $2.3 \%$ and $3.4 \%$ separately.

The cause of above phenomenon is, during the freezing period, there will appear the cracks caused by temperature shrinkage when freezing-front extend to deep slope, the new freezing-front in the soil is formed, then the moisture in soil body migrate to the cold freezing-front, so the curve of moisture here is decline. In spring, the ground temperature rises up, when it reach about $0{ }^{\circ} \mathrm{C}$, the moisture near the freezing-front begins to migrate again under the function of gravity and surface tension, and then there is the first uplift process of the moisture curve. When ground temperature is over $0.1^{\circ} \mathrm{C}$, the melting water from snow and infiltrating water near the freezing-front make the moisture curve have the second uplift process.

\section{Effect of Freeze-Thaw on Shear Strength of the Soil in the Slope}

In order to study the effect of freeze-thaw cycles, soil moisture and compaction degree on soil shear strength, the soil on the slope was conducted series of experiments. First, the basic physical parameters of the soil in the slope are shown in Table 1. 
Table 1 Basic physical properties indicators of silty clay

\begin{tabular}{lllll}
\hline Liquid Limit (\%) & Plastic limit (\%) & Plasticity index & $\begin{array}{l}\text { Maximum dry density } \\
(\mathrm{g} / \mathrm{cm} 3)\end{array}$ & $\begin{array}{l}\text { Optimum water } \\
\text { content }(\%)\end{array}$ \\
\hline 32.5 & 18.7 & 13.8 & 1.90 & 13 \\
\hline
\end{tabular}

(a)

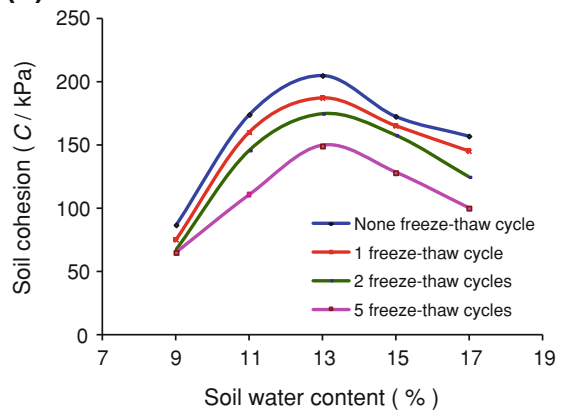

(b)

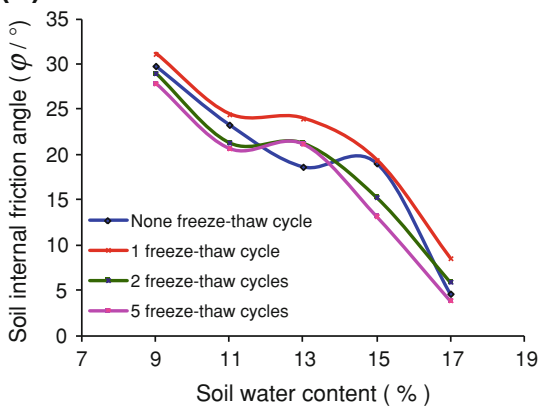

Fig. 2 Moisture-cohesion curves and moisture-internal friction curves before and after frozenthaw with $95 \%$ soil compaction

Under same $95 \%$ compaction degree, the soil samples with different water content and different freeze-thaw cycles were conducted indoor triaxial test, the results are shown in Fig. 2.

Effect of freeze-thaw cycles and water content on soil cohesion

For silty clay with $95 \%$ compaction degree, Fig. $2 \mathrm{a}$ is the relationship curve between soil moisture and soil cohesion under different freeze-thaw cycles. It can be seen that when soil moisture is close to the optimum moisture, soil cohesion reach the peak value. Soil cohesion decreases gradually with increasing freezethaw cycles, especially when soil compaction degree is bigger. Under the optimum moisture, after 1, 2, 5 freeze-thaw cycles, the soil cohesion decreases by 18,30 and $56 \mathrm{kPa}$ separately.

Effect of freeze-thaw cycles and water content on soil internal friction

For silty clay with $95 \%$ compaction degree, Fig. $2 \mathrm{~b}$ is the relationship curve between soil moisture and soil internal friction angle under different freeze-thaw cycles. It can be seen that soil internal friction angle decreases with increasing soil moisture. When soil moisture increases from 9 to $17 \%$, after 1, 2, 5 freeze-thaw cycles, the reduction value of soil internal friction angle is $64,47,46,57 \%$ separately.

On the whole, soil cohesion decreases with increasing freeze-thaw cycles. Soil internal friction increases after the first freeze-thaw cycle, and then decreases gradually in later freeze-thaw cycles. 


\section{Conclusions}

Laboratory test results showed that: the soil cohesion increases with increasing of soil moisture. When the soil water content is bigger than the optimum water content, the soil cohesion decreases with soil moisture. Under the same moisture, soil cohesion increases with increasing dry density. The internal friction angle of soil decreases with increasing moisture. Freeze-thaw had a significant effect on soil cohesion and internal friction angle. Soil cohesion decreases gradually with freeze-thaw cycles, soil internal friction increases after the first freeze-thaw cycle, then decreases gradually in later freeze-thaw cycles.

Field monitoring results show that, for the ground temperature in $1.4 \mathrm{~m}$ depth, on the top of the slope is affected by the weather temperature mostly. The kind and density of the plant on the slope also affect the ground temperature in $1.4 \mathrm{~m}$ depth. During the freezing period, there will appear the cracks caused by temperature shrinkage when freezing-front extend to deep slope, the new freezing-front in the soil is formed, then the moisture in soil body migrate to the cold freezing-front, so the curve of moisture here is decline. In spring, the ground temperature rises up, there is a longer duration of zero temperature in $1.4 \mathrm{~m}$ depth of the slope, the moisture near the freezing-front begins to migrate again under the function of gravity and surface tension, and then there is the first uplift process of the moisture curve. When ground temperature is over $0.1{ }^{\circ} \mathrm{C}$, the melting water from snow and infiltrating water near the freezing-front make the moisture curve have the second uplift process.

Because of the accumulating water within the cracks of temperature shrinkage and longer duration of zero temperature below the slope surface, the melting water was hampered, result in high water content in shallow slope, soil shear strength decreases, then cutting slope landslides.

Acknowledgments The authors would like to thank the financial supports provided by the research project of Heilongjiang provincial Science and Technology Department (GZ07 C401), and the Key project of Heilongjiang provincial Transportation Department "Highway Slope Stability and Greening by Vegetation in Cold Regions".

\section{References}

Clark MJ (1988) Advance in periglacial geomorphology. Wiley, New York, pp 325-359

Li YC, Zhao KN (2002) The analysis of landslide in k2023 of QING-Zang highway. J Geol Hazards Environ Preserv 13(4):33-35

Liu HJ, Wang PX (2006) Stability analysis of loss of stability caused by freeze and melt of earthen side slopes of highways. J Harbin Inst Techol 38(5):764-766

McRoberts EC, Morgenstern NR (1974) The stabilityof thawing slopes. Can Geotech J 11:447-469

Niu FJ, Cheng GD (2002) Study on instability of slopes in permafrost regions of Qinghai-Tibet High Plateau. In: Proceedings of the 5th international symposium on permafrost engineering. Permafrost Institute SB RAS Press, Yakutsk, pp 192-197 
Niu FJ, Cheng GD, Lai YM (2004) Instability study on thaw slumping in permafrost regions of Qinghai-Tibet Plateau. Chin J Geotech Eng 6(3):402-406

Shan W, Guo Y, Liu HJ (2009) Effect of freeze-thaw on strength and microstructure of silty clay. J Harbin Inst Techol 16:207-211

Tarr RS (1897) Rapidity of weathering and stream erosion in the arctic latitudes. J Am Geol 19:131-136

Wang BL, French HM (1995) In situ creep of frozen soil, Fenghuo Shan, Tibet Pleateau, China. Can Geotech J 32(3):545-552

Wu H, Gao W, Wang GF et al (2006) Cause and control of soil-cutting's sliding collapse in frigid zone. J Nat Disasters 15(3):66-70

Zhou YW, Guo DX (1982) Principal characteristics of permafrost in China. J Glaciol Geocryol 4:1-19

Zhu C, Zhang JX, Cheng P (1996) Rock glaciers in the central Tianshan Mountain, China. Permafr Periglac Process 7:69-78 